\title{
Transition of the Mainstream/Special Education System to the Inclusive Education System in Pakistan
}

\author{
Uzma Rafique \\ University of the Management and Technology, Lahore
}

\begin{abstract}
The purpose of this review article is to assess the best practices in inclusive education and how the transition has been affected in the developed regions (Australia, Canada, and U. K) and developing countries (India, Sri Lanka). This is done with a view to understand the nature and processes of Inclusion adopted by Pakistan for making its educational system more inclusive. A four-pillar framework is used to analyze the best practices of inclusive education. The research is based on secondary sources such as publications, articles, and reports. The findings of the research suggest that best practices of inclusive education are the development of educational policies, acceptance of change by key players, collaboration among them, training of teachers and changes in the curriculum.
\end{abstract}

Keywords:Inclusive education;Four-Pillar Framework; Development of Educational Policies; Acceptance of change; Training of teachers.

DOI: $10.7176 / \mathrm{JEP} / 10-1-11$

\author{
Abbreviations Used \\ DTSC: District Training and Support Center \\ IVS: Inclusive Voucher Scheme \\ PEP: Punjab Education Foundation \\ PIEP: Punjab Inclusive Education Project \\ UNESCO: United Nations Educational, Scientific and Cultural Organization \\ UNICEF: United Nations Children's Fund
}

\section{Introduction}

Around the world, over half a billion individuals are disabled because of various physical, mental or sensory impairments. People with disabilities encountered physical and social barriers which restricted them to access quality education. These individuals also had limited opportunities to contribute to the development of nations. The field of special education has offered an opportunity toexplore various ways of responding to the educational needs of individuals with disabilities and those who experience difficulties in learning. Initially, the special education system was introduced to offer a segregated learning environment for disabled children. Unfortunately, the segregated system made the disabled children more vulnerable to discrimination, exclusion, and marginalization (UNESCO, 2005, p. 12).

In the recent past, the special education system has been challenged because of its effectiveness and concerns for human rights (UNESCO, 2005, p. 12). As a consequence, the special educational practices have been integrated into the mainstream education. The concept of inclusive education was introduced to move the special education practices into the mainstream education system. Primarily, inclusion is a process of responding to diversity and it is about learning to appreciate the individual differences. In 1990, 'The World Declaration on Education for All' was initiated with the intentions of shifting the focus of education systems to inclusion (UNESCO, 2005, p. 14). In 2000, the United Nations Educational, Scientific and Cultural Organization (UNESCO) put forward its agenda of 'Education for All' (EPA) to combat discrimination in education and contribute to developing an inclusive society (UNESCO, 2005, p. 14). The purpose of the EPA was also to ensure that all children have access to quality education and the education system is based on equality and nondiscrimination. The inclusive education also emphasizes on creating an environment that is friendly, supportive, and welcoming for all children. It is about the active participation of all students in learning activities. Inclusion also reduces the risk of underachievement and marginalization for all learners (UNESCO, 2005, p. 15).

However, the transition from thespecial education system to inclusive education system was not an easy task. This research article is based on the review of prior literature that accessed the main requirements and key players in the transition from the segregated education system to the inclusive education. Moreover, the key facts are gathered on the impact of this transition in the developed and developing countries. The research scope is narrowed by evaluating the need for inclusive education in Pakistan and a way forward to make the educational system more inclusive in the province of Punjab, Pakistan.

\section{Research Questions}

This research study aims to address following research questions: 
- What are the main requirements for transition of education systems from special education system/ mainstream education system to inclusive education system?

- How this transition has been affected in developed countries (Australia, Canada, and U.K) and developing countries (India, Sri Lanka).

- What is the way forward for Punjab to make our educational system more inclusive from its status?

\section{Material and Methods}

In this research study, the narrative literature review is used as the main research method. The proposed research questionsare addressed in the study by reviewing different pieces of literature in the field of special education and inclusive education. Also, the domain sources and publications are related to educational sciences, special education, mainstream education, and inclusion in education. The specific case countries selected for review include developed regions of Australia, Canada, and the UK and developing regions of India and Sri Lanka. Also, for this research study, data is gathered through secondary sources such as journal articles, authentic websites, electronic databases, academic books, and publications. The third research question is addressed by evaluating reports published by the Department of Special Education, Government of Punjab.

\section{Research Findings}

The research findings are categorized into four main sections. The first section elucidates on inclusive education framework and best practices of inclusive education retrieved from relevant literature. The second section discusses the situation of inclusive education in developed regions, whereas the third section sheds light on the adoption of inclusive education in developing countries. The fourth section reflects on the implementation status of inclusive education in Punjab.

\section{Section 1: Framework for Analysis and Best Practices for Inclusive Education Framework for Analysis}

Inclusive education can be examined in the context of thedevelopment of community-based social services. A framework for analysis was developed by Davis (2005) to present the best practices of inclusive education. The inclusive education framework has four pillars, i.e., policy and legal framework, thestructure of services, human capacity and performance measures. The description of each pillar is highlighted as below:

\begin{tabular}{|c|c|}
\hline Pillar 1: Policy and Legal Framework & Pillar 2: Structure of Services \\
\hline $\begin{array}{l}\text { Policies and laws that depict internationally recognized best practices, } \\
\text { implementation strategies, collaboration, legal and policy mandates }\end{array}$ & $\begin{array}{l}\text { Types and ranges of programs } \\
\text { initiated, financial support, outreach } \\
\text { services and public awareness } \\
\text { initiatives. }\end{array}$ \\
\hline Pillar 3: H & Pillar 4: Performance Measures \\
\hline $\begin{array}{l}\text { The acquisitionof knowledge and skills for educators, through } \\
\text { professionaleducationandtraining, curriculum development activities, } \\
\text { planning and decision-makingprocesses, networking and knowledge- } \\
\text { sharing activities. }\end{array}$ & $\begin{array}{l}\text { Indicators used to evaluate the } \\
\text { outcomes of programs and services at } \\
\text { different levels such as national, } \\
\text { community, school and individual } \\
\text { level. }\end{array}$ \\
\hline
\end{tabular}

This four-pillar framework represents the system-wide view of inclusive education and facilitates in assessing the overall implementation of inclusive education. Therefore, it is used in this research to evaluate the situation of inclusive education in developed and developing countries along with the implementation of inclusive education in Punjab.

\section{Best Practices for Inclusive Education from Relevant Literature}

Best practices in inclusive education are structural and operational interventions that contribute to the enhanced provision of quality education to all children; including disabled children. One of the best practices of inclusive education is the development of inclusive education policies (UNESCO, 2005, p. 20). Based on the educational goals of a region, the educational policies are defined. Therefore, the educational goals and policies elucidate on the need for transition in the education system and consider the benefits of inclusive education practices on the society. The inclusive policies allow the educational institutions in a region to implement the changes in their education system. These policies also reflect on the role of governments in the educational reforms. For instance, in Romania, the inclusive schools were established that integrated special education with the mainstream education after the enactment of Salamanca Statement and Framework for Action on Special Education (Ghergut, 2011). Likewise, other countries have also developed inclusive policies and legislation to make changes in their education systems.

Reforming the education system is not only about putting in place the inclusive education policies, but it also requires the acceptance of the change by the key players such as teachers, students, parents, school 
administration, communities, and local and national governments (UNESCO, 2005, p. 20). The acceptance of the transition is linked with overcoming barriers such as existing attitudes and values of key players regarding the inclusive education and lack of resources to implement the new integrated education system. The willingness of teachers, parents, students, and schools to promote diversity is essential for the effective transition of the mainstream education system to the inclusive education system (UNESCO, 2005, p. 21). Particularly, teachers, educators, and in-school professional staff have higher responsibilities to develop an inclusiveculture; therefore, their acceptance is crucial in the transition (Ognen, 2010). Overall, acceptance to change leads to a change in the attitude and role behavior of key players and the availability of their support to all students in the classrooms. Along with this, the cooperation between key players in the education system is another requirement for the transition (UNESCO, 2005, p. 22). For instance, the participation of family members of a disabled child in school activities and their interaction with teachers and school administration are prerequisites to foster an inclusive culture in the school. Beveridge (2004) focused on home-school relations and the importance of partnerships in the effective development of an inclusive culture in the educational institutions. Moreover, the cooperation between educators and governments are necessary to promote diversity in the inclusive schools (UNESCO, 2005, p. 22).

The transition also requires revision of the curriculum for children with disabilities. Specifically, in the inclusive context, it is vital to develop a curriculum that ensures equal human rights and provides equal learning opportunities for all students (Vrasmas, 2014). In other terms, the inclusive approach to curriculum reflects that every student should gain benefit from the quality education. The revised curriculum for inclusive education also concentrates on child-centered, equality-based and interactive teaching methods (Vrasmas, 2014).

The best practices of inclusive education under four pillars of inclusive education framework are summarized as below:

\begin{tabular}{|l|}
\hline \multicolumn{1}{|c|}{ Policy and Legal Framework } \\
\hline Defining education goals and inclusive education policies \\
\hline Support fromthe legislation that reflects on human rights \\
\hline Flexible funding and support of governance for inclusive education. \\
\hline Coordination and partnership between key players \\
\hline \multicolumn{1}{|c|}{ Structure and Types of Services } \\
\hline Acceptance of change by key players Human Capacity \\
\hline School reforms \\
\hline Inclusive education initiatives at different levels \\
\hline Revision of curriculum \\
\hline \\
\hline Training for teachers and educators \\
\hline Participatory program planning \\
\hline Performance Measures \\
\hline Need-based student assessment \\
\hline Performance assessments
\end{tabular}

\section{Section2: Situation of Developed Countries}

Inclusive education has been adopted as a policy goal in many countries (Skidmore, 2004). However, the shift from the mainstream education to the inclusive education in developed countries is not same as it is in developing countries. The need for inclusive education was stronger in the developing regions than developed regions because of two reasons. Firstly, the number of disabled people is more in the developing regions than developed regions (UNESCO, 2005, p. 12). Secondly, the education system of developing countries is not wellestablished (Gowder, 2014). This part of the article reflects on the effects of the transition in the education system in developed regions of Australia, Canada, and the UK and developing regions of India and Sir Lanka.

\section{Inclusive Education in Australia}

The transition to inclusive education in Australia has been a vital part of theeducational discourse in the past two decades (Anderson and Boyle, 2015). A shift from the special education for disabled children and children with learning difficulties to the high-quality education for all children has been observed in Australia. The Australian Government made it obligatory for educational providers to show compliance with the Disability Discrimination Act of 1992 and the Disability Standards for Education proposed in 2005 (Malaquias, 2016). The eight jurisdictions of Australia have also developed policies for inclusive education (Anderson and Boyle, 2015). With each Australian state, a taskforce works to ensure the successful implementation of inclusive education. The Australian government also provides enhanced funding for promoting the new education system. The transition has affected the curriculum and pedagogy as a consistent curriculum has been developed to offer equal access to 
education to all students anddecrease the risk of marginalization for disabled and non-indigenous students in Australia. Moreover, the transition has a positive influence on the school-home interaction and students' accomplishment (Anderson and Boyle, 2015). However, it is found that eight educational jurisdictions in the country have enacted inclusive education in different ways which led to inconsistent educational outcomes and the level of access to all students in Australia (Anderson and Boyle, 2015).

\section{Inclusive Education in Canada}

Like other developed countries, inclusive education is an important concern for Canada. The Canadian government has developed policies to promote inclusive education in the region (Rieser, 2012, p. 11). Inclusive education became an official policy in Canada in 1968 and subsequently, it becomes a part of Legislative Act of 1985. Based on this legal framework, it is required that every school should be inclusive. The integration of the special education with the mainstream education is accompanied by structural changes in the educational institutions of Canada along with changes in the teaching methodologies and strategies and the curriculum (Rieser, 2012, p.11).The inclusive education enabled educators in Canada to provide an equal access to education to indigenous and non-indigenous students. The inclusive education also contributed in enhancing the participation of disabled individuals in the society. The best practices implemented in the region include anunderstanding of inclusive education, individualized educational planning and support base for all students. Also, block funding is provided for inclusive schools and adequate teacher training contributed in human capacity development. Besides the positive outcomes of the transition in Canadian education system, the change in the attitude of teachers and their preparation for inclusive education are major challenges affected the transition (McCrimmon, 2014). However, through supportive communication and collaboration and offering training to teachers in inclusive educational institutions of Canada, these issues can be resolved (Richmond, et.al, 2013).

\section{Inclusive Education in the UK}

The inclusive education has been promoted in the UK (Rieser, 2012, p.11). The transition from mainstream schools or special education system to inclusive education affected the education policies, practices, and culture of educational institutions of the region. The government of UK encouraged inclusion on three basic dimensions, i.e., developing inclusive education policies, creating inclusive cultures, and promoting inclusive practices in schools, colleges, and universities (UNESCO, 2005, p. 25). Furthermore, the UK disability movement has played a major role in the transition. The inclusive education in terms of the UK disability movement means that structures, relationships, and cultures in the educational institutions foster an equity environment for all students (Ainscow, Booth and Dyson, 2004). The conversion of the mainstream education to the inclusive education has positive consequences in the UK. For instance, schools and local authorities have developed plans to enhance access to children with disabilities (European-agency.org, n.d). The curriculum arrangements, such as school trips and homework are designed in ways that ensure egalitarianism among all students. Special education schools along with regular schools in the UK gained an opportunity to become teaching schools that offer training to new school staff (European-agency.org, n.d). Therefore, a sustainable school-led education system has been developed with the implementation of inclusive education in the UK (European-agency.org, n.d).

\section{Section 3: Situation of Developing Regions Inclusive Education in India}

Unlike developed regions, the education system in the developing countries is not well-established which creates hindrance in the effective implementation of the inclusive education. India is one of the countries that faced difficulty in providing equal education to all. The number of disabled people in India is 26 million, almost $2.1 \%$ of its total population (Sharma and Das, 2015). The government of India has taken various initiatives and has developed national policies and programs for the inclusive education, but these attempts do not have a significant impact yet. For instance, Able Disabled All People program was initiated in Mumbai to ensure inclusion of disabled student in themainstream learning environment. Likewise, Integrated Child Development Services (ICDS) Scheme was introduced to ensure early childhood care in India. Besides these interventions, the country is lagging behind in providing quality education to people with disabilities because of limited understanding of disability, inability to conceptualize inclusive education, and lack of teachers' preparation(Sharma and Das, 2015). Additionally, the lack of adequate resources, inappropriate teaching practices, and the lack of effective leadership supportare other factors that negatively affected the implementation of theinclusive education system in India (Sharma and Das, 2015). Also, the number of trained personnel for inclusive education practices does not meet the needs of special children in India (UNICEF, 2003). Also, the curriculum does not cater to the needs of disabled children due to which the region has not so far accomplished the goal of inclusive education (UNICEF, 2003).

\section{Inclusive Education in Sri Lanka}


Sri Lanka has not yet transited from the mainstream education system to the inclusive education system. Like other developing regions, Sir Lanka is also struggling to improve its education system and provide quality education for disabled children. The Government of Sri Lanka has passed different policies and legislation for the inclusion of disabled individuals in the society. The basic human rights of disabled persons are guaranteed under the Act for the Protection of Rights of Persons with Disabilities 1996 (Muttiah, Drager and O'Connor, 2016). However, policies for people with disabilities are not adequately implemented in the region (Rieser, 2012 , p. 111). Moreover, no specific law focuses on the education of disabled children (Muttiah, et.al, 2016). Besides the lack of legal support, the negative attitude linked with disability limit disabled children to attend schools. In Sri Lanka, children with disabilities gain education either through special education schools or special education units within regular schools (Muttiah, et.al, 2016). The limited number of special education schools in the rural areas of all three provinces of Sir Lanka creates a barrier for disabled children to access quality education (Muttiah, et.al, 2016). Furthermore, the lack of support from the administration of regular schools, limited awareness of parents regarding educational opportunities for disabled children, and an inadequate number of qualified teachers refrained Sri Lanka to implement inclusive education system.Furuta (2006) recommended that inclusive education should be fitted in the environment of each school by creating awareness about inclusive education among teachers, parents, and school administration.

\section{Section 4: Inclusive Education in Punjab, Pakistan \\ Need for Inclusive Education in Punjab}

Being a developing country, Pakistan is also facing various challenges while implementing the inclusive education. The existing status of inclusive education in a particular province of Pakistan, i.e. Punjab is reviewed here. Currently, the prevalence rate of disabilities in Punjab is $10 \%$ and the percentage of school-aged (i.e. between age 4 and 16) disabled children is $20 \%$. It means that for every 1 million population, 100,000 people are disabled in Punjab. Out of this 100, 000 disabled population, 20,000 are children between age 4 and 16 (Department of Special Education Punjab Report, 2014). Overall, the number of children with disabilities in Punjab is 2,000,000 (Department of Special Education Punjab Report, 2014).

Furthermore, the number of primary education schools in Punjab is 38, 632 and the number of special education schools is only 239 which reveal that the special education schools are far less than regular schools in Punjab. The number of students enrolled in special education schools of Punjab is found to be 27, 606 compared to 4,177, 797 enrolled students in primary education schools (Department of Special Education Punjab Report, 2014). Moreover, a limited number of teacher educators at District Training and Support Center (DTSC) created a barrier in providing access to education fordisabledchildren(Department of Special Education Punjab Report, 2014). These facts and figures highlight the dire need for inclusive education in Punjab.

\section{Path towards Inclusive Education in Punjab}

In order to switch from the mainstream and special education system to the inclusive education system, the Special Education Department, Government of Punjab initiated a 'Punjab Inclusive Education Project' (PIEP) in two Southern Districts of Punjab, i.e.Bhawalpur and Muzaffargarh in2014 (Department of Special Education Punjab Report, 2014). The project was intended to complete by the end of 2017 with a total provision of Rs. 1176 million (Department of Special Education Punjab Report, 2014). The major goals of PIEP encompassed the identification of disabled children in two districts of Punjab and place them in the right inclusion friendly mainstream school. Subsequently, the disabled children enrolled in the mainstream schools would be monitored and they would be retained by providing an inclusive environment and adequate teacher and peer support. PIEP also has a goal of providing teachers' training to enhance their performance in an inclusive school environment (Department of Special Education Punjab Report, 2014).Along with this, PIEP aimed to improve the infrastructure of themainstream, but inclusive schools. By June 2017, PIEP has achieved its major goals by identifying 7685 disabled children in Punjab and by enrolling 1024 children in mainstream schools (PIEP Report, 2017). Almost 14, 844 teachers were trained and awareness about inclusive education was increased to 23,300 people (PIEP Report, 2017).

In 2015, the Special Education Department of Punjab also initiated another pilot project named Voucher Scheme for Inclusive education in PIEF managed schools in four major divisions, i.e. Multan, Vehari, Rawalpindi, and Lahore (PIEP Report, 2017). The pilot project was intended to enhance public-private partnership with the Punjab Education Foundation (PEP) with the provision of Rs. 1176 million (Department of Special Education Punjab Report, 2015). The goals of Inclusive Voucher Scheme (IVS) were similar to PIEF. The project aligns with the Constitution of Pakistan, which states that all children of age 5-16 have right to access free and compulsory education (Department of Special Education Punjab Report, 2015).

By October 2017, the number of disabled children identified in IVS was 1043 and almost 252 inclusive schools were established in three areas of Punjab (PIEP Report, 2017). Moreover, almost 845 teachers were trained under the project. The achievement status of PIEP and IVSrevealed that these projects have significantly 
improved the special education conditions in Punjab and facilitated in transforming the mainstream education system tothe inclusive education system. However, the future prospects of the Department of Special Education should be based on the deeper reflection on diversity in education and implement inclusive education through policy implications. Moreover, it is required to understand the diversity-related impact on the curriculum design and teaching strategies and teachers' developmentin inclusive schools.

\section{Observations, Conclusions, and Discussion of Results General Findings}

The findings of literature helped in addressing the first research question. The inclusive education framework helped in assessing the best practices based on four pillars. The importance of policy and legal framework is reflected along with the kinds and ranges of inclusive education services and programs. The inclusive education framework also analyses the education status of a region in terms of human capacity development and evaluates the performance measures. The best practices encompass the development of inclusive policies, interaction and cooperation among different players, redesigning of the curriculum, training of teachers and educators and needbased student assessment.

\section{Findings for Developed Countries}

Different research works also assisted in addressing the second research question and understanding the implementation status of the inclusive education in developing and developed regions. In the developed regions of Australia, Canada, and the UK, the inclusive education system is positively established due to the development of policies by their respective national governments (Malaquias, 2016; Rieser, 2012). The integration of the special education in the mainstream education has significantly improved the educational opportunities for children with disabilities in developed regions. The revision of curriculum, teachers' preparation and training, and collaboration among key players in the education sector of these regions are few outcomes of the implementation of inclusive education (Ainscow, Booth and Dyson, 2004; Richmond, et.al, 2013; Rieser, 2012).

\section{Findings for Developing Countries}

The situation of developing countries is different from the situation of developed regions. The case of India and Sri Lanka indicated that the regions so far do not succeed in implementing the inclusive education. The major barriers in promoting inclusive education in developing countries are limited understanding of disability and lack of teachers' preparation (Sharma and Das, 2015) and the lack of support from school administration along with a limited number of specialized schools (Muttiah, et.al, 2016).

\section{Findings for Punjab}

The reports from the Department of Special Education, Punjab facilitated in responding to the third research question. The current status of disabled children and the number of specialized schools in Punjab highlighted the need for promoting inclusive education in Pakistan. The two projects, i.e., PIEP and IVS were initiated recently to address the diversity and inclusion issues in the educational institutions of Punjab. The projects were intended to provide access to quality education to all children including disabled children. The achievement status of both projects particularized a shift in the education system. However,still, there is a long way to completely move to the inclusive education in Punjab, Pakistan.

\section{References}

Ainscow, M., Booth, T., and Dyson, A. (2004). Understanding and developing inclusive practices in schools: a collaborative action research network. International Journal of Inclusive Education, 8(2), pp.125-139.

Anderson, J. and Boyle, C. (2015). Inclusive education in Australia: rhetoric, reality and the road ahead. Support for Learning, 30(1), pp.4-22.

Beveridge, S. (2004). Children, Families, and Schools: Developing Partnerships for Inclusive Education. New York: Routledge.

Davis, R. T. (2005). Child Welfare Reform in a Global Context: A Blueprint for Analysis. Child Welfare Specialty Section. Washington, DC: NASW.

Department of Special Education Punjab Report (2014). The government of Pakistan, Planning Commission PC1 Forum: Punjab Inclusive Education Project. A report published by the Department of Special Education, Punjab.

Department of Special Education Punjab Report (2015).The government of Pakistan, Planning Commission PC1 Forum: 'Voucher Scheme for Inclusive Education at PEF Schools for Mainstreaming of Special Needs Children' Punjab Inclusive Education Project. A report published by the Department of Special Education, Punjab. 
European-agency.org (n.d). UK (England) - Special needs education within the education system. Retrieved from: https://www.european-agency.org/country-information/united-kingdom-england/national-overview/specialneeds-education-within-the-education-system

Furuta, H. (2006). Present Status of Education of Children with Disabilities in Sri Lanka: Implications for Increasing Access to Education. The Japanese Journal of Special Education, 43(6), pp.555-565.

Ghergut, A. (2011). National Policies on Education and Strategies for Inclusion; Case Study Romania. Procedia - Social and Behavioral Sciences, 29, pp.1693-1700.

Gowder, S.J.T. (2014). Current Education System and Policy in Developing and Developed Countries-An Overview. Journal of Socialomics, 3.

Malaquias, C. (2016). Australia and the Right to Inclusive Education. Retrieved from: http://www.globiobservatory.org/australia-and-the-right-to-inclusive-education/

McCrimmon, A. (2014). Inclusive Education in Canada. Intervention in School and Clinic, 50(4), pp.234-237.

Muttiah, N., Drager, K. and O'Connor, L. (2016). Special Education in Sri Lanka: A snapshot of three provinces. Disability Studies Quarterly, 36(2).

Ognen, S. (2010). Principles of the Inclusive Education and the Role of Teachers and In-School Professional Staff. The Journal of Special Education and Rehabilitation, 11(1/2).

PIEP Report (2017). Voucher Scheme for Inclusive Education at PEF Schools for Mainstreaming of Special Needs Children (Pilot Project at Lahore, Multan, and Rawalpindi). A report published by the Department of Special Education, Punjab.

Richmond, D.M., Irvine, A., Loreman, T., Cizeman, J.L., and Lupart, J. (2013). Teacher Perspectives on Inclusive Education in Rural Alberta, Canada. Canadian Journal of Education, 36, 1, pp.195-239.

Rieser, R. (2012). Implementing Inclusive Education. UK: Commonwealth Secretariat.

Sharma, U. and Das, A. (2015). Inclusive education in India: past, present, and future. Support for Learning, 30(1), pp.55-68.

Skidmore, D. (2004). Inclusion: The Dynamic of School Development. Buckingham: Open University Press.

UNESCO (2005). Guidelines for Inclusion: Ensuring Access to Education for All. Retrieved from: http://unesdoc.unesco.org/images/0014/001402/140224e.pdf

UNICEF (2003). Examples of Inclusive Education: India. UNICEF Regional Office for South Asia.

Vrasmas, T. (2014). Curriculum for Children with Disabilities in Inclusive Education. A Literature Review. Procedia - Social and Behavioral Sciences, 127, pp.336-341. 